\title{
Pensar y hacer la democracia, sobre Francisco Delich
}

Juan Russo ${ }^{1}$

Es difícil reseñar en pocas páginas la figura de un entrañable amigo con el que estuvimos en contacto hasta hace pocos días atrás. Conocí a Francisco en 1982, después de terminada la Guerra de Malvinas. Recién egresado de la carrera de sociología en la Universidad Nacional de San Juan, una de las pocas de Argentina que sobrevivió (diezmada) al golpe de estado, y ante la prohibición de hacer política, comencé con otros sociólogos (Alicia Vera, Raúl Moreno, Susana Rodríguez)a organizar el Colegio de Sociólogos de San Juan,(y con Edelma Enríquez y Daniel Filmus) la Federación Nacional de Sociología. Había en los jóvenes de entonces una enorme necesidad de encontrar una explicación desde las ciencias sociales a lo que había ocurrido en Malvinas, y al mismo tiempo necesitábamos marcos de explicación más amplios, que trascendieran el nacionalismo parroquial. Escribí a Francisco, entonces Secretario ejecutivo de CLAC$\mathrm{SO}$, invitándolo a dar una conferencia sobre Malvinas. Tuve una respuesta inmediata agradeciendo y confirmando su visita en el mes junio. El país dejaba atrás el silencio del infierno autoritario y comenzaban a escucharse voces que nos recordaban que existía posibilidades más amplias para analizar y transformar la sociedad y la política. Delich fue una de esas voces, que generosamente acercaron el mundo al país, y que mostró un futuro diferente. Recuerdo mi escepticismo ante los primeros pasos de la transición democrática de entonces, y la respuesta esperanzada de Francisco: «la sociedad tiene memoria, verás... la sociedad tiene memoria» (siempre admiré su optimismo).Delich dio así la primera conferencia sociológica en San Juan desde el golpe de estado del 76. Su conferencia y las reuniones que mantuvo con colegas, contribuyó a nuevos aires y a los primeros debates sobre la democracia en el país. Francisco fue uno de los primeros sociólogos en pensar la transición democrática en Argentina. Además de la democracia, su tema de estudio fue la modernización, en Argentina todavía

\footnotetext{
${ }^{1}$ Docente de la Universidad de Guanajuato (México).
} 
una promesa y un problema complejo. La modernización lo mantuvo en un diálogo constante con Gino Germani, a quien conoció en París, y de quien recordaba con humor que en su primer diálogo Germani le dijo: joven, aqui no tiene nada que hacer, si quiere estudiar en serio vaya a los Estados Unidos. Francisco pensaba desde los clásicos (en particular Weber y Durkheim) , y miraba siempre al horizonte futuro. Su pregunta diaria parecía ser: ¿En qué punto de la historia estamos? No he conocido a nadie con tanta conciencia de la temporalidad, es decir de la época en que vivía, y de su lugar en ese tiempo. Creo que ello tuvo consecuencias importantes sobre su comportamiento. El primero era la búsqueda del sentido de los hechos políticos y sociales. ¿Por qué ocurrían, que los justificaba socialmente? Y el segundo, una enorme humildad y apertura: ¿Que hay de nuevo para leer? Preguntó en 1993 en Madrid, mientras cenábamos con Ramón Cotarelo; ¿qué hay de nuevo para leer? Me preguntó en 2015 en su casa de San Vicente. Siempre explorando nuevos conocimientos. En París en el 2002, en épocas que escribía su Crisis en la crisis, me dijo» en teoría política prefiero Italia, Inglaterra-Estados Unidos, y Francia,» en ese orden». Sus amplitud de conocimientos de ciencia social le permitían pasar desde la política, a la sociología y al análisis de la cultura. Ello puede verse en su variada producción, que va desde El desempleo de masas en argentina (trabajo riguroso de investigación sociológica) hasta Metáforas de la sociedad argentina (una colección de ensayos) con el destacable Metáfora de la sociedad enferma, que explica de modo weberiano el sentido de la acción política autoritaria en Argentina. O producciones como el sistemático Repensar América Latina, al exploratorio La sociedad invisible, la cultura de la ingobernabilidad en América Latina. La modernización como preocupación dominante de sus investigaciones, lo acercó a los temas del cambio social y político, así como a alejarse de posiciones dogmáticas y de la intolerancia de cualquier tipo. En México, en una conferencia inaugural del año académico de Sociología en 2006, cuando los alumnos preguntaron sobre la misión de la carrera, respondió: la sociología nació cuando se dejó de lado la religión. Dejar de lado la explicación dogmática, Delich en eso fue un ejemplo acabado. Lo religioso comprende todo tipo de sacralización, todo objetivo que se aleje de buscar conocimiento. Así, en la informada introducción a un reciente libro que coordinara: Marx, ensayos plurales, considera al marxismo soviético, ante todo como una iglesia regida por los dogmas y la escolástica propios de una religión. Gran parte del marxismo latinoamericano en el siglo XX fue visto como parte de una «nueva evangelización». 
Como ocurrió con Germani, el camino de Delich no fue cómodo en Argentina. En particular si se piensa que fue un honesto intelectual de acción, donde sus preocupaciones sobre democracia y la modernización, se transformaron en misiones ciudadanas. Desde CLACSO, dirigió Critica y Utopía, una revista pionera en América Latina sobre temas de democracia. Su gestión como director ejecutivo a favor de los profesores expulsados, de los exiliados, entrevistando a presidentes de diversos países latinoamericanos para que recibieran a argentinos perseguidos, fue una tarea que quedó en la memoria y el corazón de intelectuales de la región. Recuerdo en su primer reencuentro con Leopoldo Allub en Argentina, Leopoldo le agradeció que en años muy difíciles del Proceso militar, su gestión desde CLACSO le permitiera trabajar en una universidad de Estados Unidos. Delich fue un valiente sin grandilocuencias. Me contó que en la etapa final del gobierno militar, lo citaron en un organismo policial para intimidarlo a que cesara la publicación de Critica y Utopía, a lo que Francisco respondió: todo lo que me ha dicho envíemelo por escrito, y siguió publicando la revista. Su tono siempre era bajo, aunque estuviera diciendo las cosas más desafiantes.

Recién egresado de Sociología, fui designado Decano normalizador de la Facultad de ciencias sociales en San Juan. Por supuesto, muy pronto la esperanza democrática chocó con las herencias y los límites que la provincia impone, y los obstáculos que encontramos para el cambio, contrastaban (para mi dramáticamente) con los cambios que Delich lograba como Rector de la UBA. La gestión de Delich fue un faro democrático para todo el país. La democratización de la universidad era entonces una prioridad y había que hacerlo asumiendo todas las consecuencias. Delich encontró así que democratizar la universidad no podía darse sin construir simultáneamente una agenda para la calidad. Universidad de calidad para todos hoy es sentido común, en aquella época eran muy pocos los que así lo concebían. Dos objetivos muy vastos para cumplirlos en muy poco tiempo (808 días, como lo recordó en uno de sus últimos libros). Delich polarizaba con sus proyectos de transformación académica democrática y cosmopolita.

Más tarde fui asesor junto con María Grossi y Patricia Angel, en la Secretaría de Educación de la nación, cargo en el que Francisco encontró dificultades internas para gestionar cambios. Por ello decidió dejar el cargo y una nueva secretaria que Alfonsín le ofreciera. Por qué no lo aceptas? Le pregunté. Para qué, me respondió, no podría hacer nada ahí». Detestaba ocupar cargos sólo para flotar. Estaba haciendo mi doctorado en Italia, 
cuando fue designado Rector de la Universidad Nacional de Córdoba. A mi regreso al país, que duró muy poco, pude colaborar con la creación del Centro de estudios avanzados, y me encargó organizar la primera versión de la Maestría en Relaciones internacionales. Recuerdo una reunión inicial presidida por Francisco con Cacho Ortega y Cesar Tcach, donde trazó las principales líneas de lo que sería un centro académico de innovación. Pensaba que sería muy positivo para la Universidad de Córdoba, reunir un grupo de intelectuales formados en el exterior, con experiencias organizativas y académicas diferentes. En la gestión pública fue siempre de conducta intachable caracterizándose por una gran austeridad y transparencia en el uso de los recursos. «En esta Universidad hay un solo Delich, y cuando deje de ser rector, habrá un solo Delich», afirmó como Rector de la Universidad Nacional de Córdoba. Creador de instituciones, sensible ante los cambios de la época, «la mirada debe cambiar cuando cambian las cosas», la honestidad fue un valor innegociable en Delich y uno de sus principales capitales, además claro, de un amigo enorme que me acompañará siempre. No le agradaban los halagos, era una persona de posiciones claras y de fuertes embates.

Las democracias a veces tienen suerte y a veces mala suerte. La fortuna (como decía Maquiavelo) puede decidir sobre los líderes de un momento. La democracia argentina tuvo suerte en tener a Delich. Fue al mismo tiempo, como en momentos raros de nuestra historia, uno de sus constructores más leales y al mismo tiempo uno de sus mejores evaluadores. Desde la perplejidad que me genera llegar a Buenos Aires o a Córdoba y no encontrarlo para conversar sobre Argentina; me queda agradecer a la vida y al propio Francisco haber compartido más de treinta años. 